\title{
Towards Energy Self-consumption and Self-sufficiency in Urban Energy Communities
}

\author{
Valeria Todeschi ${ }^{1,2}$, Paolo Marocco ${ }^{1}$, Guglielmina Mutani ${ }^{1,3^{*}}$, Andrea Lanzini ${ }^{1,4}{ }^{\text {, Massimo Santarelli }}{ }^{1}$ \\ ${ }^{1}$ Department of Energy, Politecnico di Torino, Corso Duca degli Abruzzi 24, Turin 10129, Italy \\ ${ }^{2}$ Future Urban Legacy Lab - FULL, Politecnico di Torino, Via Agostino da Montefeltro 2, Turin 10134, Italy \\ ${ }^{3}$ Responsible Risk Resilience Centre - R3C, Politecnico di Torino, Corso Castelfidardo 22, Turin 10128, Italy \\ ${ }^{4}$ Energy Center Lab, Politecnico di Torino, Via Paolo Borsellino 38, Turin 10138, Italy
}

Corresponding Author Email: guglielmina.mutani@polito.it

https://doi.org/10.18280/ijht.390101

Received: 10 December 2020

Accepted: 6 February 2021

\section{Keywords:}

energy resilience, solar cities, selfconsumption, self-sufficiency, electric energy storage, PV-battery system, urban energy community, residential energy solutions

\begin{abstract}
In Europe, $70 \%$ of citizens live in urban areas and consume around $75 \%$ of the primary energy supply. In order to reduce the impact of energy consumption and improve the competitiveness of local energy systems, Energy Communities may help to address the challenges of urban sustainability and energy security through local energy production and self-consumption. Solar, biomass and wind are the main sources of renewable energy that are generally used in cities. However, not all the sources available in urban environment are usable, due to the limited availability, or other technical or non-technical limits and constraints. In order to promote renewable energy technologies in buildings it is necessary to consider architectural, cultural, energy, technical and economic feasibility. This work defines a methodology for the optimal design of grid connected PV-battery systems in urban environments. The model was applied to two districts located in the city of Turin with the aim of evaluating the technical feasibility of combining multiple residential users at city level. The purpose of this work is to promote self-consumption and self-sufficiency from the network, using the integration of solar energy with PVbattery systems, and to reduce electrical losses in favor of both the single user and the distribution system. Results show that different values of self-sufficiency and selfconsumption can be reached depending on the shape and dimension of each building. It was shown that it is possible to satisfy the current requirements to become an Energy Community in an urban environment with good levels of self-sufficiency.
\end{abstract}

\section{INTRODUCTION}

The concept of the energy community (EC) has been introduced by two European directives: the re-cast Renewable Energy Directive n.2001/2018 (RED II) and the Internal Electricity Market Directive n.944/2019 (IEM) as part of the European Clean Energy Package. The aim is to provide the design of two new legal entities able to promote the collective self-consumption of renewable energy with the possibility of energy sharing: the "Renewable Energy Communities" (RECs) and the "Citizens Energy Communities" (CECs) [1].

In Italy, in agreement with the Clean Energy Package, the National Energy and Climate Plan (ENCP) was introduced in 2019. The five pillars are: decarbonization, energy efficiency, energy security, internal energy markets and research, innovation and competitiveness. In line with these pillars and the two EU Directives above, the National Law 8/2020 promotes some measures regarding the environment, security and energy. Especially, the article 42bis introduces two configurations for sharing renewable electricity among citizens and final users. The first one is the collective selfconsumer that produces renewable electricity for its own consumption and can store or sell the surplus amount to the grid. The collective self-consumer comprises of at least two single users and one renewable plant connected to them that are located in the same building or condominium, who act collectively. The second configuration is the renewable energy community (REC) which extends the previous concept to multi-building users. Both mechanisms have the objective of increasing the efficiency in the low-carbon energy production with a hourly and seasonal matching between onsite supply and demand (i.e. high energy independence, selfsufficiency and self-consumption) so as to reduce the economic and environmental costs of energy and also combat energy poverty [2-4].

In order to establish a collective self-consumption scheme or a REC it is necessary that: (i) the production plants, from renewable sources, entered into operation after March $1^{\text {st }}$ 2020 and the capacity of each plant should not exceed 200 $\mathrm{kW}$; (ii) the production plants and the withdrawal points must be connected to the low voltage distribution grid, through the same transformer substation; (iii) the participants in a collective self-consumption scheme must be in the same building or condominium; (iv) the exchange of energy produced must take place through the existing distribution network; (v) general charges must be applied to energy withdrawn from the grid and to the shared energy.

In Italy, the Piedmont Region was the first to promote the institution of ECs with the Regional Law 12/2018. In order to establish the ECs in the Piedmont territory, the minimum requirements that must be met by an $\mathrm{EC}$ have been identified in the Regional Decree n.18-8520/2019: (i) the electrical contiguity, the members of the EC must belong to territorially 
contiguous electrical "areas" (i.e. same MV/LV transformer substation); (ii) the amount of electricity consumption, annual electricity consumption must be at least $0.5 \mathrm{GWh}$; (iii) the annual self-consumption must be greater than or equal to $70 \%$, of which at least $50 \%$ must be generated from locally available renewable energy sources (RESs); (iv) the plurality of actors, there must be a plurality of energy producers and consumers.

The goal is to plan sustainable and resilient territories, through the use of RESs that play an important role in the reduction of greenhouse gas emissions and in the promotion of energy self-sufficiency [5]. One of the main solutions is the large-scale urban generation of renewable energy [6]. Solar, biomass and wind are the most commonly available RESs that can be used in cities to promote self-consumption [7]. In these cases, a strategy that facilitates the selfsufficiency is the integration of battery storage systems in connection with RES technologies which supply energy in a discontinuous way according to climatic conditions [8]. The use of a battery storage system is fundamental in the achievement of energy security at urban level where an energy mix of RESs is not available [9].

From an economic point of view, self-consumption is convenient for consumers if the cost of locally produced renewables is lower than retail electricity prices [10]. The Italian legislation has introduced incentives aimed at encouraging the collective self-consumption and the institution of ECs including storage systems. In particular, the National Decree of $15^{\text {th }}$ September 2020 introduces: (i) the incentives for self-consumption energy for electricity equal to $0.10 € / \mathrm{kWh}$ for collective self-consumers and 0.11 $€ / \mathrm{kWh}$ for RECs (the incentive is paid for a period of 20 years); (ii) the compensation for unused charges for the transport and distribution of energy withdrawn from the low voltage network: $0.01 € / \mathrm{kWh}$ for collective self-consumers and $0.008 € / \mathrm{kWh}$ for RECs.

Therefore, in order to increase the use of RES in cities, the concepts of collective self-consumers and REC have been investigated in this work for an Italian city. Starting from the analysis of the relationship between urban environment and energy resilience and exploring the effect of morphology on energy performance and solar productivity of residential buildings $[11,12]$; the aim of this work is to better exploit the PV production by introducing electric energy storage systems. A methodology to improve the self-consumption and selfsufficiency in high-density built context combining multiple homes at city level was assessed. More in detail, different scenarios using Li-ion battery systems were investigated in two districts of Turin (Italy). The simulation was carried out for one year with hourly time resolution, based on real monthly electricity consumption.

The remaining part of the paper proceeds as follows: Section 2 describes the methodology used to assess the load and PV profiles of residential buildings and the PV-grid sizing approach; Section 3 shows the case study describing the characteristics of the population, the building stock and the urban environment, and the electrical consumption distributions at district level; in Section 4 main results obtained for different scenarios are indicated; and the last section summaries main research findings. Future work will take into account existing incentives for the promotion of energy communities and the use of renewable energy technologies financing mechanism.

\section{MATERIALS AND METHOD}

Electrical consumption of buildings depends on socioeconomic aspects, on day type and on the number of occupants, but also by its surroundings and local climate conditions able to affect for example the daylight [13-15]. Regarding the PV production on rooftops [16], the solar energy potential depends on the suitable roof area available, on the roof slope, and on the roof orientation (south-faced tilted roofs have a higher productivity). In this work, two districts in the city of Turin with different socio-economic characteristics and urban environments were analyzed. The balance between electrical consumption and PV production was investigated with the aim to improve the selfconsumption and the self-sufficiency of residential buildings using storage systems. These two aspects were investigated using the following indexes:

- The self-consumption $(S C / P)$ is defined as the ratio between the energy production that is locally used $(S C)$ and the total PV production $(P)$.

- The self-sufficiency $(S C / C)$ is defined as the ratio between the energy production that is locally used ( $S C)$ and the total energy consumption $(C)$.

Figure 1 shows the methodology used for the optimal design of grid connected to the PV-battery systems in urban environment.

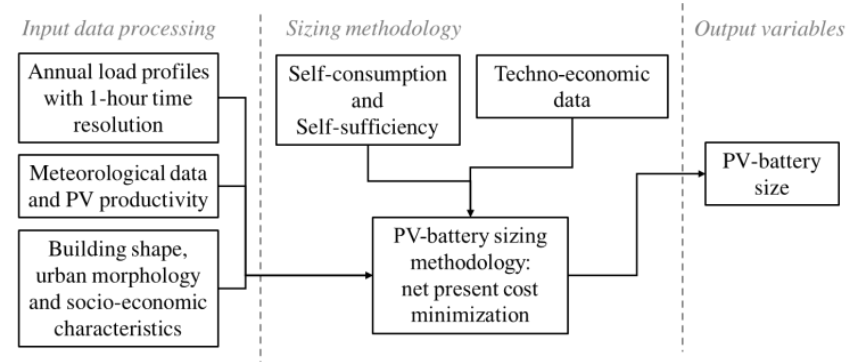

Figure 1. Flowchart of methodology

\subsection{Input data processing}

In this subsection the input data used to investigate the optimal design of grid connected to the PV-battery systems for a group of residential users are described. The annual load profiles with 1-hour time resolution and the PV productivity were assessed for each user at building level with the support of geographic information systems (GIS).

Hourly load profiles of residential buildings were obtained from monthly measured data of two consecutive years (2016 and 2017) of over 154 buildings. The annual load profile with 1-hour time resolution was generated at building level using as reference the hourly profiles of typical seasonal days (i.e. winter, spring, summer and autumn) for 380-470 residential families with 2.15 components considering both working and non-working days [17]. The average cost of withdrawing electricity from the grid (i.e. $0.22 € / \mathrm{kWh}$ ) and the feed-in cost (i.e. $0.10 € / \mathrm{kWh}$ ) for prosumers was also derived for this database. In addition, knowing the electrical consumption of each user, with the use of GIS tools, the distribution of electrical consumption at district level has been quantified.

The potential of solar energy in the residential sector was assessed taking into account several criteria used to evaluate the rooftop suitability. The main characteristics, which affect the use of the roof for the installation of PV panels, are the 
roof shape, architectural characteristics, morphological context, building codes, and regulations. According to the literature review [18-23], the criteria identified in this work to evaluate the roof suitability for the installation of PV panels are:

- Roof shape, the roof area had to be greater than $50 \mathrm{~m}^{2}$ and the roof slope had to be between $20^{\circ}$ and $45^{\circ}$ that corresponds to pitched roofs;

- $\quad$ Superstructure constraints, the presence of disturbing elements on the roof limits the suitability;

- Roof orientation, north-facing rooftops were excluded;

- Solar irradiation, roof area must receive at least 1,200 $\mathrm{kWh} / \mathrm{m}^{2} /$ year (considering also the shadow effect);

- Energy and environmental regulations, the installed electric power, $P_{e l}$, (in $\mathrm{kW}$ ) must be greater than or equal to the value calculated with this equation: $P_{e l}=$ $(1 / K) \cdot A$, where $P_{e l}$ is the installed electric power $(\mathrm{kW})$, $K$ is a coefficient equal to $50\left(\mathrm{~m}^{2} / \mathrm{kW}\right)$ after January $1^{\text {st }}$ 2017 , and $A$ is the footprint area of the building $\left(\mathrm{m}^{2}\right)$.

- Heritage and aesthetic criteria, heritage buildings in which the installation of PV panels is forbidden, due to the aesthetic qualities of some urban areas, were excluded.

With the use of GIS tools, a georeferenced database was created in order to assess the criteria. The potential rooftop area for the installation of PV technologies was identified for each building at district level taking into account the orientation (south, east and west). The hourly radiation data have been elaborated for one year using the PVGIS portal (https://re.jrc.ec.europa.eu/pvg tools/en/\#PVP). The solar energy that can be produced on each roof was assessed considering standard PV systems with an efficiency of $14 \%$ and an inclination of $20^{\circ}$. Therefore, knowing the maximum installable power for each roof (according to the suitable rooftop area), a procedure to identify the optimal design of grid connected to PV-battery systems was applied (see Section 2.2).

\subsection{Sizing methodology}

Energy balance simulations have been performed over a reference year considering 1-hour time resolution. An energy management strategy was developed to manage the operation of the power system. The key-decision parameter for the battery operation is represented by battery SOC, which is the ratio between the stored energy and the total battery capacity.

More in detail, when the PV power is lower than the electrical demand, the battery intervenes in discharging mode until reaching the minimum state-of-charge SOC. Finally, electricity is bought from the grid when both PV and battery systems are not enough to cover the whole electrical load. In case instead the PV power is greater than the electrical demand, the surplus renewable energy is first used to charge the battery and then (when the maximum battery SOC is reached) sold to the grid (Table 1).

The battery SOC was defined as follows:

$$
\begin{aligned}
\operatorname{SOC}(t)=\operatorname{SOC}(t-1) & +\frac{P_{B T, c h}(t-1) \cdot \Delta t \cdot \eta_{B T, c h}}{\operatorname{Cap}_{B T}} \\
& -\frac{P_{B T, d c}(t-1) \cdot \Delta t}{\eta_{B T, d c} \cdot \operatorname{Cap}_{B T}}
\end{aligned}
$$

where, $\operatorname{Cap}_{B T}$ is the battery rated capacity, $P_{B T, c h / d c}$ corresponds to the charging/discharging power of the battery,
$\eta_{B T, c h / d c}$ is the battery charging/discharging efficiency and $\Delta t$ is the time step of the simulation.

The optimal sizing methodology employs the particle swarm optimization (PSO) algorithm to search for the optimal system configuration (i.e. PV rated power and BT capacity), which allows to minimize the net present cost (NPC) of the power system. The metaheuristic PSO technique was adopted since it is a highly performant and robust method when dealing with the optimal design of power systems [24]

The NPC was computed in the following way:

$$
N P C=C A P E X_{0}+\sum_{j=1}^{n} \frac{O M C_{t o t, j}}{(1+d)^{j}}+\frac{R C_{t o t, j}}{(1+d)^{j}}
$$

where, $C A P E X_{\text {tot }, 0}$ represents the total initial investment cost, $O M C_{\text {tot }, j}$ and $R C_{\text {tot }, j}$ correspond respectively to the operation/maintenance and replacement costs referred to the $\mathrm{j}$-the year, $n$ is the system lifetime and finally $d$ is the discount rate (Table 1).

The $O M C_{t o t, j}$ term is derived as:

$$
\begin{gathered}
O M C_{t o t, j}=O M C_{P V, j}+O M C_{B T, j}+C_{e l, b u y, j} \\
-C_{e l, s e l l, j}
\end{gathered}
$$

where, $O M C_{P V, j}$ and $O M C_{B T, j}$ correspond to the operation/maintenance costs associated to the PV and battery component, respectively. $C_{e l, b u y, j}$ is the yearly cost due to electricity bought from the grid and $C_{e l, s e l l, j}$ is the yearly revenue due to renewable electricity sold to the grid (Table 1). A constraint on the self-consumption and self-sufficiency can also be included within the optimization routine:

$$
\begin{aligned}
& S C / P \geq(S C / P)_{\text {target }} \\
& S C / C \geq(S C / C)_{\text {target }}
\end{aligned}
$$

where, $(S C / P)_{\text {target }}$ and $(S C / C)_{\text {target }}$ correspond to the target self-consumption and self-sufficiency values that the PV-battery system must achieve at the minimum system cost.

Table 1. Main techno-economic parameters used in the PVbattery optimal sizing (Li-ion battery) [25-27]

\begin{tabular}{cc}
\hline Parameter & Value \\
\hline & $1,000 € / \mathrm{kWh}$ if $\mathrm{P}>20 \mathrm{~kW} ; 1,600$ if \\
PV system investment cost & $6 \leq \mathrm{P} \leq 20$ and $2,000 € / \mathrm{kWh}$ if \\
$\mathrm{P}<6 \mathrm{~kW} *$ \\
PV O\&M cost & $2 \% / \mathrm{y}$ (of Inv. cost) \\
BT investment cost (with & $500 € / \mathrm{kWh} *$ \\
extra-cost of hybrid inverter) & $250 € / \mathrm{kWh}$ \\
BT replacement cost & 10 years \\
BT lifetime & 1 \\
Maximum BT SOC & 0.1 \\
Minimum BT SOC & 0.95 \\
BT discharging efficiency & 0.95 \\
BT charging efficiency & $0.10 € / \mathrm{kWh}$ \\
Cost of PV electricity sold to & \\
the grid & $0.22 € / \mathrm{kWh}$ \\
Cost of electricity withdrawn & $5 \%$ \\
from the grid & 20 years \\
Discount rate & \\
System lifetime &
\end{tabular}




\section{CASE STUDY}

The methodology presented in the previous section was applied to two districts located in the city of Turin, Italy. According to the annual report of the city [28], electricity consumption in the residential sector from 2004 to 2009 is quite constant with values close to $2.5 \mathrm{TWh} /$ year; from 2010 to 2013 there was a slight decrease of $6 \%$. This trend is presumed to be due to the increase in the energy efficiency of household appliances and electronic equipment. According to the electrical consumption data used in this work, on average the annual electrical consumption of a Turin family is about 1,600 kWh/fam/year (reference years: 2016-2017).

Starting from a database elaborated in GIS, the characteristics of the population and the characteristics of the building stock were analysed to identify homogeneous areas. One of the aims was to investigate how and at what extent the variables related to energy, social and urban morphology influence the electricity consumption and the solar energy production of the residential building stock. Two districts called Crocetta (with an extension of 199,251 $\mathrm{m}^{2}$ ) and Arquata (with an extension of $108,926 \mathrm{~m}^{2}$ ) were selected as homogenous zones [16]. In these districts $80 \%$ of the buildings were built before $1945,15 \%$ in 1946-1980, and only $5 \%$ after 1992 . Crocetta is a district located near the historic city center and is one of the most prestigious residential areas. The $90 \%$ of buildings are residential compact condominiums (with an $S / V$ of $0.48 \mathrm{~m}^{2} / \mathrm{m}^{3}$ ), and there are 220 buildings with about 2,500 apartments. Arquata is a social housing district built in 1920 and includes 52 buildings (with an $S / V$ of $0.41 \mathrm{~m}^{2} / \mathrm{m}^{3}$ ) for a total of about 1,070 apartments.

The characteristics of the city are described below with an in-depth investigation of the selected districts. In Figure 2 the annual per capita income distribution in $€$ /year (updated to 2009) for 94 statistical zones of Turin (for two of them the information is not available) is indicated. The map shows that the richest areas are located in the city center and in the hilly area East of the city, while the poorest areas are in the peripheral areas North and South of the city.

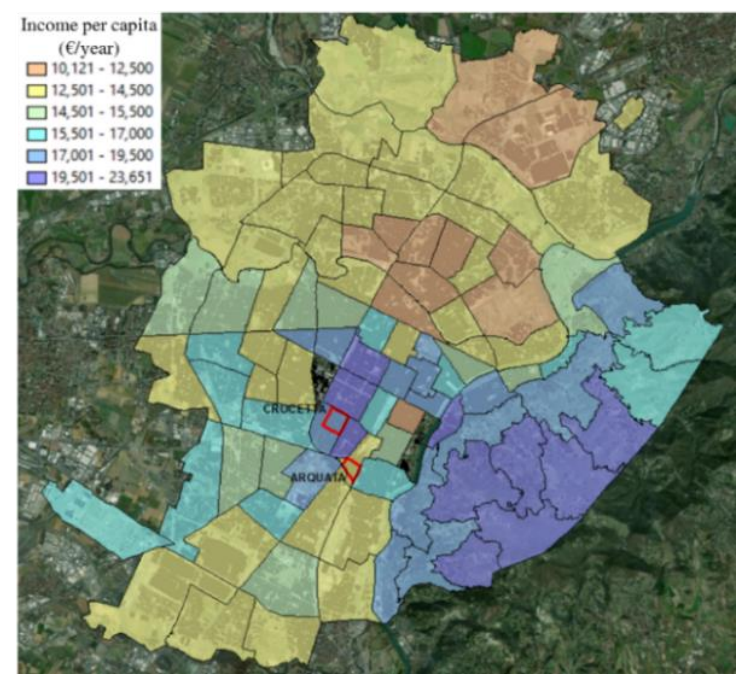

Figure 2. City of Turin: per capita income (at 2009) at statistical zone scale and identification of two case studies

The average annual income is about $15,500 € /$ year, with a maximum of $23,651 € /$ year and a minimum of $10,122 € /$ year. The two zones selected for this analysis are indicated in red.
Table 2 describes the main socio-economic characteristics for these two districts. The information was elaborated using the ISTAT database (updated to 2011) at census section scale and the income database (updated to 2009) at statistical zone scale. Crocetta is a richer area with an annual income of $4,000 € /$ year higher than Arquata. The other indicators are quite similar, the greatest differences are the percentage of foreigners (highest in Arquata) and the percentage of graduates which is $32 \%$ in Crocetta and only $8 \%$ in Arquata.

Table 2. Characteristics of the population in the two districts

\begin{tabular}{cccc}
\hline Variable & Unit & Crocetta & Arquata \\
\hline N. of inhabitants & - & 3,703 & 1,756 \\
N. of families & - & 1,867 & 937 \\
Components for family & Inh/fam & 2.03 & 1.88 \\
Income per capita & $€ /$ year & 18,016 & 14,114 \\
Foreigners inhabitants & $\%$ & 7 & 14 \\
Average age & - & 48 & 49 \\
Old-age-dependency ratio $^{1}$ & - & 242 & 294 \\
Dependency ratio $^{2}$ & $\%$ & 71 & 65 \\
Graduates inhabitants $^{\text {Employed inhabitants }}$ & $\%$ & 32 & 8 \\
Employed $^{2}$ & $\%$ & 95 & 77 \\
\hline
\end{tabular}

With regard to the building stock, in Turin there are almost 60,000 buildings, of which $76 \%$ are residential. The residential buildings are mainly large and compact condominiums, with low values of surface-to-volume $(S / V)$ ratio. The $55 \%$ has an $S / V$ of lower than $0.45 \mathrm{~m}^{2} / \mathrm{m}^{3}$. On average, the apartments have a heated surface that varies between 75 and $95 \mathrm{~m}^{2} /$ apart; Figure 3 shows the heated surface per apartments $\left(\mathrm{m}^{2} /\right.$ apart $)$ at statistical zone scale. Comparing Figures 2 and 3 it is possible to observe that, obviously, there is a relation between income and apartments surface. This is just an example of the relationships between the socio-economic variables. In a future work this aspect will be further explored by analysing other areas of the city.

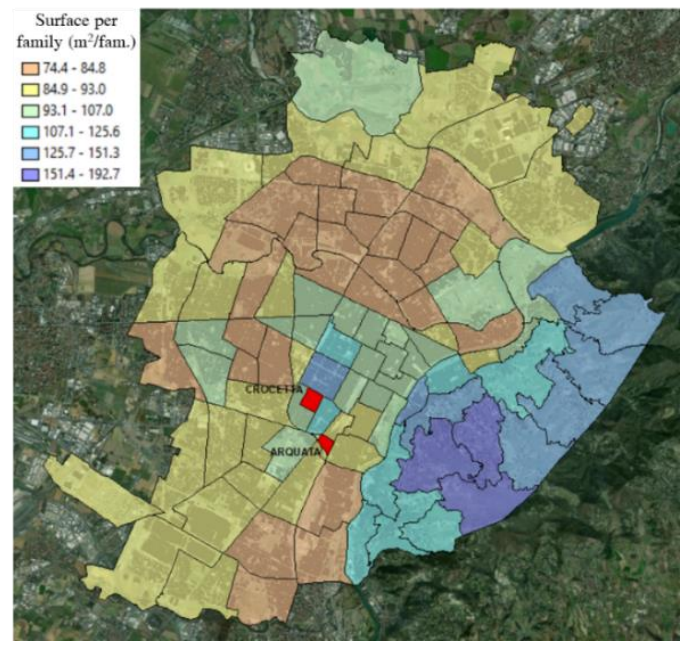

Figure 3. City of Turin: per capita income (at 2009) at statistical zone scale and identification of two districts

\footnotetext{
1 The old-age-dependency ratio is the ratio between the number of inhabitants aged 65 and over (age when they are generally economically inactive) and the number of inhabitants aged between 15 and 64 . The value is expressed per 100 persons of working age (15-64). Values higher than 100 indicate a greater presence of elderly population than young population.

2 The dependency ratio is an age-population ratio of those typically not in the labor force (dependents aged 0-14 and over the age of 65) and those typically in the labor force (the total population aged 15-64).
} 
Table 3 describes the main characteristics of the residential building stock in the two districts. The information was elaborated using the Municipal Technical Map (updated to 2019) at building scale and the ISTAT database (updated to 2011) at census section scale. From the analysis emerged that the shape of the building is quite similar in the two districts, but there is a substantial difference, which is the heated surface per apartment. In fact, wealthy families have larger apartments, and the heated surface is $104 \mathrm{~m}^{2} /$ apart in Crocetta and $70 \mathrm{~m}^{2}$ /apart in Arquata.

Table 3. Characteristics of the of the residential building stock in the two districts

\begin{tabular}{cccc}
\hline Variable & Unit & Crocetta & Arquata \\
\hline N. of buildings & - & 246 & 52 \\
N. of residential buildings & - & 220 & 47 \\
Total footprint area & $\mathrm{m}^{2}$ & 55,697 & 19,151 \\
$\quad$ (residential) & & 303,856 & 89,574 \\
Gross floor area (residential) & $\mathrm{m}^{2}$ & 0.39 & 0.39 \\
Surface-to-volume ratio & $\mathrm{m}^{2} / \mathrm{m}^{3}$ & 104 & 70 \\
Heated surface per apartment & $\mathrm{m}^{2} / \mathrm{apart}$ & 11 & 23 \\
N. of apartments per building & - & 11 & \\
(average) & - & &
\end{tabular}

\subsection{Electrical consumption and PV production analysis}

This subsection describes the electrical consumption and the PV production of the two districts selected. Starting from the database elaborated in GIS and collecting a large amount of data about the energy-use at building level, the monthly electrical consumption considering only residential users have been georeferenced with the information of the address. About 150 users were selected considering on average an annual electrical consumption of $1,500 \mathrm{kWh} /$ fam/year (anomalous data were excluded from the analysis). In Crocetta and Arquata districts the measured consumption refers to 80 and 42 residential buildings respectively.

Figures 4 and 5 show the residential users: in green the residential buildings selected for the analysis of which the electricity consumption is known and in red the other residential buildings are indicated.

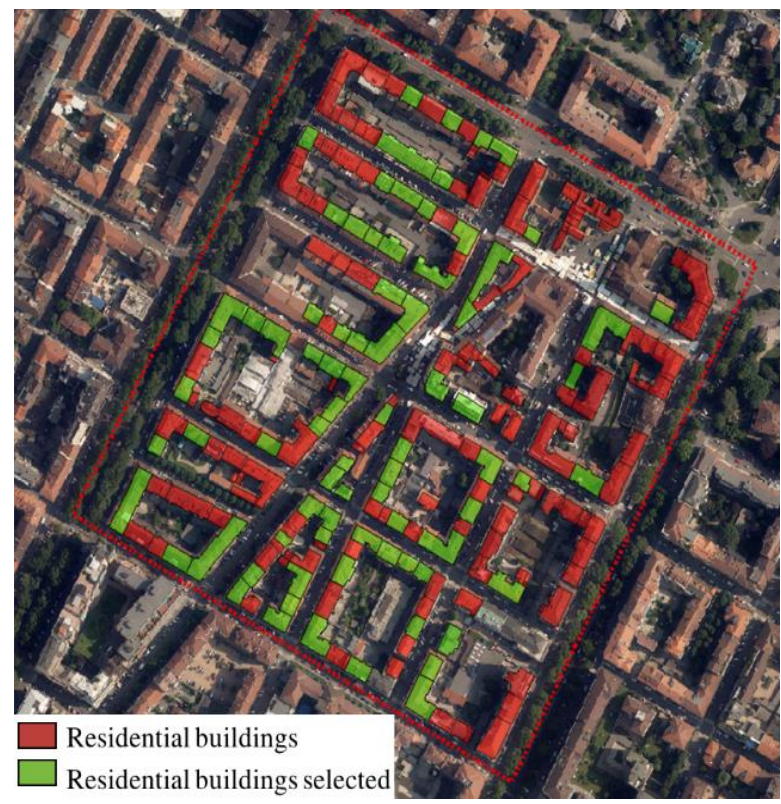

Figure 4. Crocetta district with residential buildings

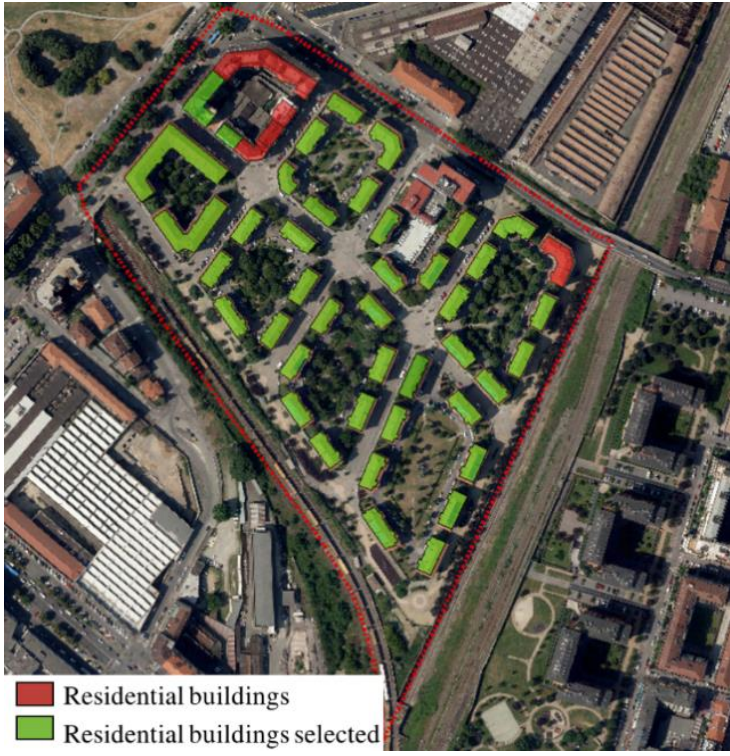

Figure 5. Arquata district with residential buildings

The monthly electrical consumption from January 2016 to December 2017 have been elaborated. Data were provided by the electric services company of the city, IREN. Figure 6 shows the measured monthly average daily electrical consumption per family $(\mathrm{kWh} /$ fam/day) referring to the period from January $1^{\text {st }} 2017$ to December $31^{\text {st }} 2017$.

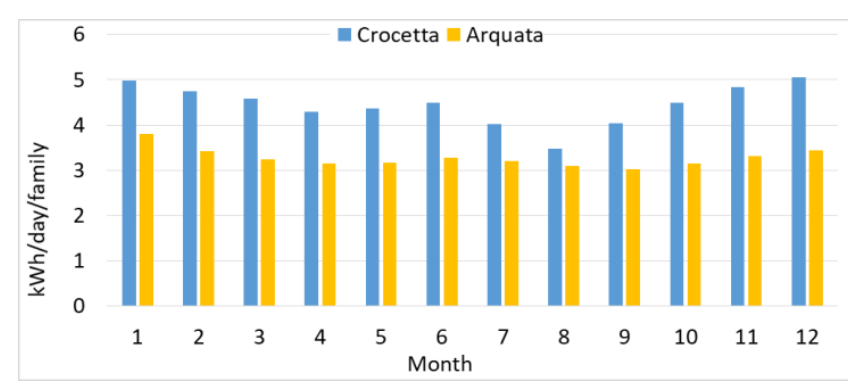

Figure 6. Measured monthly average daily electrical consumption ( $\mathrm{kWh} /$ day/family) of 122 residential users in the two districts for the year 2017

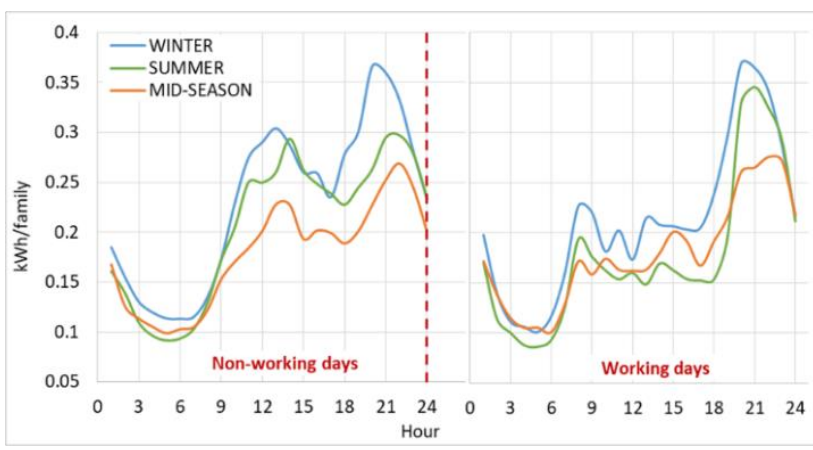

Figure 7. Electrical hourly consumption $(\mathrm{kWh} / \mathrm{fam})$ in the Crocetta district for the year 2017

From monthly data, and knowing the hourly profiles of some typical days, the energy demand profile for one year with 1-hour time resolution was elaborated. In Figure 7 the average hourly load profiles per family in Crocetta district for non-working days (Sunday) and working days (Monday) distinguishing winter, summer and mid-season periods are reported. 
Regarding the solar energy production, the quota of suitable rooftop area for the installation of PV technologies was analysed in GIS using the Municipal Technical Map (updated to 2019) and the Digital Elevation Model (updated to 2018) with a precision of 0.5 meters. The potential area was calculated for each roof according to several criteria (i.e. orientation, slope, constrains). In Crocetta and Arquata districts there are respectively 80 and 42 residential buildings with a potential PV area of $17,861 \mathrm{~m}^{2}(73 \%$ of total roofs area) and $12,217 \mathrm{~m}^{2}$ (74\% of total roofs area). This potential area considers only the best-exposed solar area and the presence of disturbing elements equal to $15 \%$ of roof surface [18].

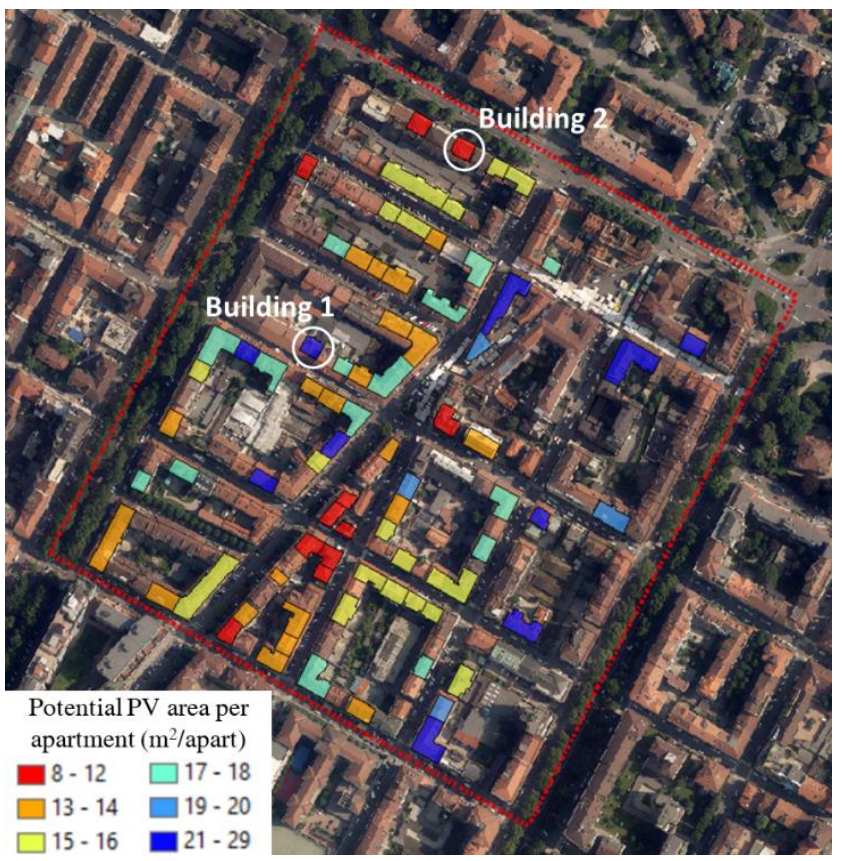

Figure 8. Crocetta district with the potential roof-integrated PV area per apartment

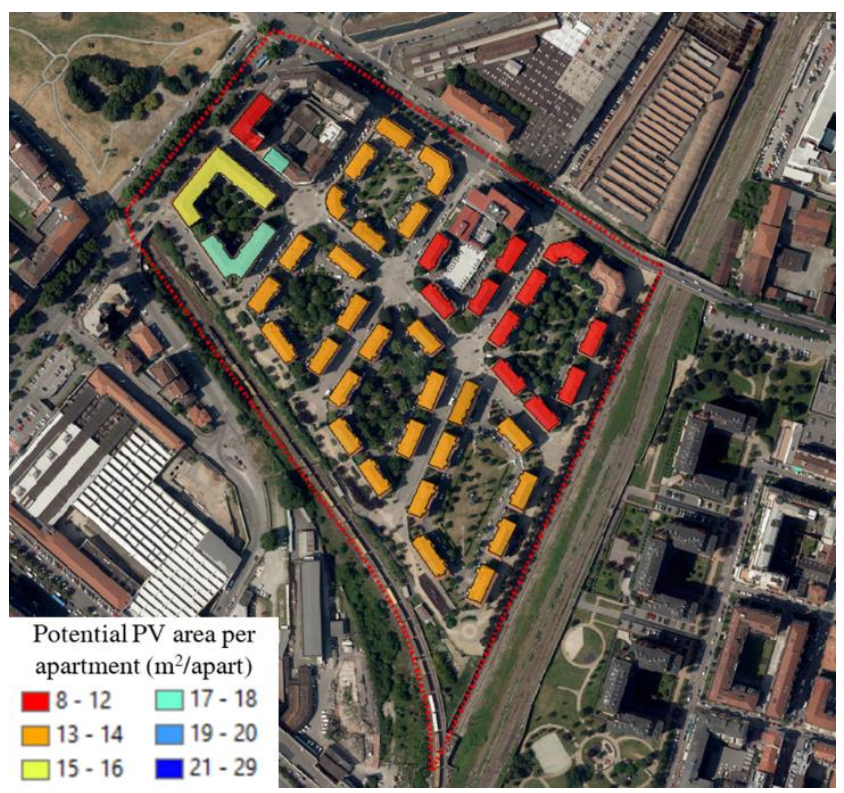

Figure 9. Arquata district with the potential roof-integrated PV area per apartment

An interesting indicator calculated at building scale is the ratio between the potential area for PV installation and the number of apartments ( $\mathrm{m}^{2} /$ apart). On average in Crocetta the potential $\mathrm{PV}$ is $16 \mathrm{~m}^{2}$ /apart (Figure 8), while is $12 \mathrm{~m}^{2}$ /apart for Arquata (Figure 9). This value is because in Crocetta the heated surface per apartment is $104 \mathrm{~m}^{2} /$ apart while in Arquata, that is a social housing zone with low-income, the heated area per apartment is $70 \mathrm{~m}^{2} /$ apart. In Figures 8 and 9 the potential PV area according to the number of apartments ( $\mathrm{m}^{2} /$ apart) at building level is indicated. The solar energy production depends not only on the quota of the potential PV area, but also on the area orientation; in fact, according to the exposure there are different values of solar irradiation [16]. Table 4 shows the main information used as input data. Electrical consumption depends significantly on income, and in this case the consumption per apartment is higher in Crocetta.

Table 4. Electrical consumption and PV production data of the residential buildings in the two districts

\begin{tabular}{cccc}
\hline Variable & Unit & Crocetta & Arquata \\
\hline N. of buildings & - & 80 & 42 \\
N. of apartments & - & 1,174 & 976 \\
Annual consumption per & $\mathrm{kWh} / \mathrm{fam}$ & 1,660 & 1,180 \\
family & & & \\
Potential PV area & $\mathrm{m}^{2}$ & 17,861 & 12,217 \\
Max PV power & $\mathrm{kW}$ & 2,223 & 1,527 \\
\hline
\end{tabular}

\section{RESULTS AND DISCUSSION}

In this work, different residential districts with various building dimension and shape were investigated with the aim to improve self-consumption $(S C / P)$ and self-sufficiency $(S C / C)$ with roof-integrated PV technologies in the city of Turin. At building level each house individually attempts to match energy demand and supply, and when the energy demand cannot be met by the PV-battery system of that building, it is satisfied from the grid. While at district level demand shortages are satisfied from the solar energy produced by the entire district [29], in fact with the establishment of REC it is possible to further optimize power demand and supply. Referring to the constraint in the Regional Decree n.18-8520/2019 for the establishment of ECs, the self-consumption limit of $S C / P \geq 70 \%$ was considered, and different scenarios were investigated with the aim to improve the self-sufficiency $(S C / C)$. If the PV energy production is low, the $S C / P$ is high, because all the selfproduced energy is consumed; in this case the $S C / C$ is low. To increase the $S C / C$, it is necessary to produce more PV energy, but then $S C / P$ decreases. The ideal solution would be to have both $S C / P$ and $S C / C$ equal to 1 , but techno-economic limitations will occur by increasing both $S C / P$ and $S C / C$ when reaching certain thresholds [4].

Scenarios analyzed in this work are indicated below:

- In scenario 1 the size of PV-battery system was identified according to the optimal configuration without limits (S1).

- In scenario 2 the PV-battery system was sized to achieve at least $70 \%$ of $S C / P$ (according to the requirement in the Regional Decree) (S2).

- From scenario 3, considering the $S C / P$ limit (70\%), the PV-battery system was sized to achieve different levels of self-sufficiency $(S C / C)$. 
The analysis was conducted at building and district levels. The results at building level of two buildings with different shapes located in Crocetta district are described below. Table 5 shows the main characteristics of the two buildings in Crocetta (see Figure 8). The buildings have the same orientation, roof type, surroundings context, type of user (i.e. residential user with high consumption), and the potential PV area is very close, with the substantial difference that 6 families live in building 1, while 16 families live in building 2. So even if the annual consumption per family is similar, the electrical demand of building 1 is $10,622 \mathrm{kWh} /$ year while is $32,832 \mathrm{kWh} /$ year in building 2 . This difference depends on the shape and dimension of the building (or compactness), in fact the first building has only 3 floors, the other one 8 floors. Consequently, the potential area for each family to produce electricity from PV panels will be higher in the first case (with $25 \mathrm{~m}^{2} / \mathrm{fam}$ ) than in the second one (with $10 \mathrm{~m}^{2} / \mathrm{fam}$ )

Table 5. Characteristics of two buildings in Crocetta district

\begin{tabular}{cccc}
\hline Variable & Unit & Building 1 & Building 2 \\
\hline Height & $\mathrm{m}$ & 12 & 30 \\
Surface-to-volume ratio & $\mathrm{m}^{2} / \mathrm{m}^{3}$ & 0.30 & 0.22 \\
N. of apartments & - & 6 & 16 \\
Annual consumption & $\mathrm{kWh} / \mathrm{fam}$ & 1,770 & 2,052 \\
per family & $\mathrm{m}^{2}$ & 150 & 170 \\
Potential PV area & $\mathrm{kW}$ & 19 & 21 \\
Max PV power & 25 & 10 \\
Max PV area per family & $\mathrm{m}^{2} / \mathrm{fam}$ & & \\
\hline
\end{tabular}

In Table 6 there are the information of PV rated power and BT capacity for different scenarios with $S C / C$ values.

In the first scenario (S1), the model identifies the optimal system configuration without limits, and for these buildings, the two indicators $S C / P$ and $S C / C$ reached close values (52$51 \%$ and $32 \%$ respectively). The optimal PV size is $7 \mathrm{~kW}$ for building 1 and $21 \mathrm{~kW}$ for building 2, with which, however, $70 \%$ of $S C / P$ is not reached. Unlike building 1 , it can be notice that the maximum installable PV size -due to the shape and the dimension of the building (with greater number of families, therefore greater consumption but similar potential PV area)- was reached by building 2 in S1. As batteries are not cheap, it was found to not be required within the optimal configuration in S1. In fact, batteries were used only when constraints on $S C / P$ and $S C / C$ were introduced (from S3).

In the second case (S2), a self-consumption of at least $70 \%$ has been imposed, and this has reduced the quota of PV installed at the expense of self-sufficiency ( $S C / C$ equal to $27 \%$ ). Also in S2, the BT was not necessary (the smaller the $\mathrm{PV}$, the more $S C / P$ increases).

From S3, different configurations have been investigated in order to have the $S C / P \geq 70 \%$ and different levels of $S C / C$ up to the maximum achievable. The self-sufficiency constraint (from S3) introduces the need for a battery. From these results the main difference between the two buildings emerged: (i) building 1 can achieve higher values of selfsufficiency with $S C / C$ equal to $93 \%$; (ii) while building 2 with a high consumption compared to the installable PV potential cannot go beyond a self-sufficiency of $59 \%$, and given that the maximum PV potential was used immediately to reach an $S C / P$ of $70 \%$, the PV production remains constant, and to increase the $S C / C$ it is necessary to drastically increase the size of the BT. By increasing the $S C / C$ of the building the BT size increases to a point where it becomes very sharp (e.g. S6 for building 1, S4-S6 for building 2); it corresponds to unfeasible solution for a technical-economic point of view.

Table 6. Annual results at building level: comparison between two buildings in Crocetta district

\begin{tabular}{ccccccc}
\hline & \multicolumn{3}{c}{ Building 1 } & \multicolumn{3}{c}{ Building 2 } \\
Scenario & Input & \multicolumn{2}{c}{ Output } & \multicolumn{2}{c}{ Input } & \multicolumn{2}{c}{ Output } \\
& $\boldsymbol{S C / C}$ & PV & BT & SC/C & PV & BT \\
& \% & kW & kWh & \% & kW & kWh \\
\hline S1 & 32 & 7 & 0 & 32 & 21 & 0 \\
S2 & 27 & 4 & 0 & 27 & 13 & 0 \\
S3 & 50 & 8 & 9 & 50 & 21 & 37 \\
S4 & 60 & 10 & 13 & 55 & 21 & 71 \\
S5 & 70 & 12 & 18 & 57 & 21 & 221 \\
S6 & 97 & 17 & 1,787 & 59 & 21 & 1,188 \\
\hline
\end{tabular}

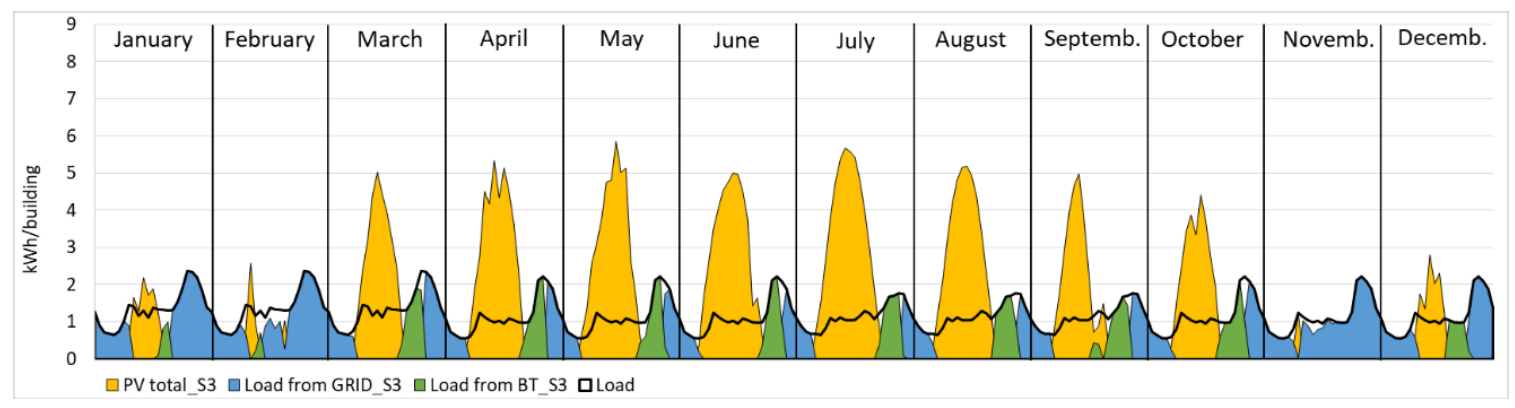

Figure 10. Hourly results for 12 typical days each representative of a specific month of the year (2017): Building 1, Scenario 3

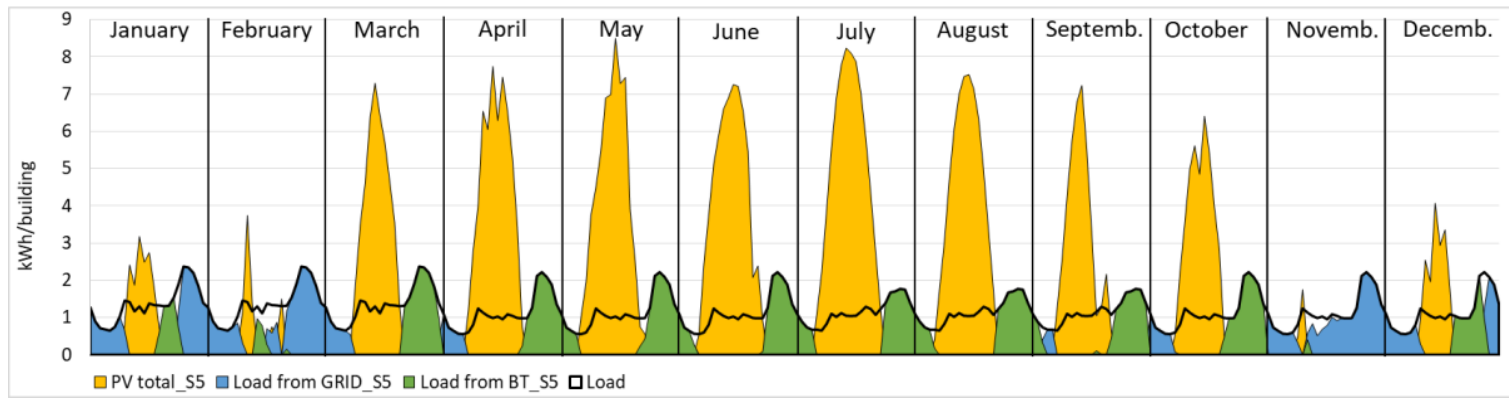

Figure 11. Hourly results for 12 typical days each representative of a specific month of the year (2017): Building 1, Scenario 5 
What is interesting about the data in Table 6 is that, taking into account the limit of $S C / P \geq 70 \%$, building 1 can achieve an $S C / C$ of $70 \%$ with $12 \mathrm{~kW}$ of PV (where the maximum installable power is $19 \mathrm{~kW}$, see Table 5) and $18 \mathrm{kWh}$ of BT; while building 2 can achieve an $S C / C$ of $50 \%$ with $21 \mathrm{~kW}$ of $\mathrm{PV}$ (that is the maximum installable power) and $37 \mathrm{kWh}$ of BT. Obviously this depends on the electrical consumption of buildings and on the PV potential (according to the usable area and the orientation). In Figures 10 and 11 the main hourly results of building 1 for S3 and S5 referring to 12 typical monthly days are indicated. In Figure 10 from March to October only a quota of energy demand was covered by PV and BT. In Figure 11 for the same months the energy demand is almost totally covered. In this first analysis, taking into account only the building shape, it is emerged that small buildings with lower consumption are better suited to achieve higher levels of $S C / P$ and $S C / C$ than large and compact condominiums. In general, $S C / P$ and $S C / C$ depends on building shape, roof type, solar exposition, type of user, surroundings context and local climate conditions. Therefore, in future work these aspects will be investigated comparing several areas in the city of Turin.

Therefore, in case of a group of residential buildings with different shapes and electrical consumption, when willing to optimize $S C / P$ and $S C / C$ it is necessary to move from the building scale to the district one.

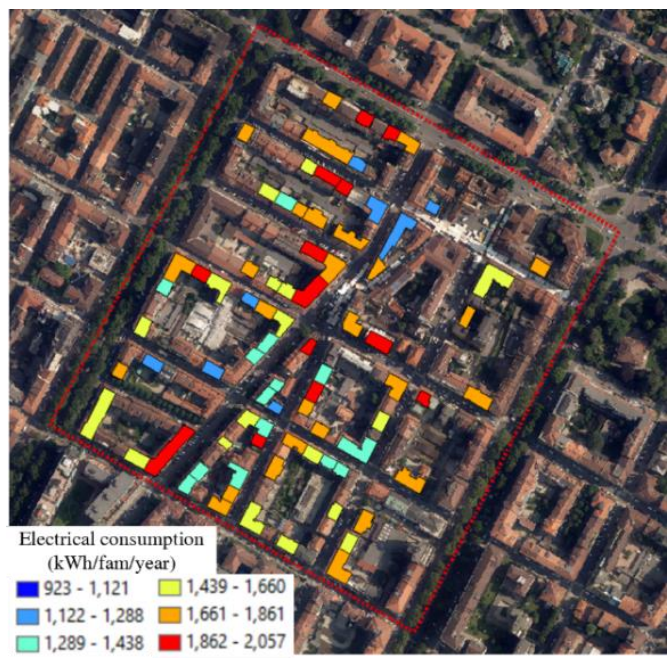

Figure 12. Annual consumption per family in Crocetta

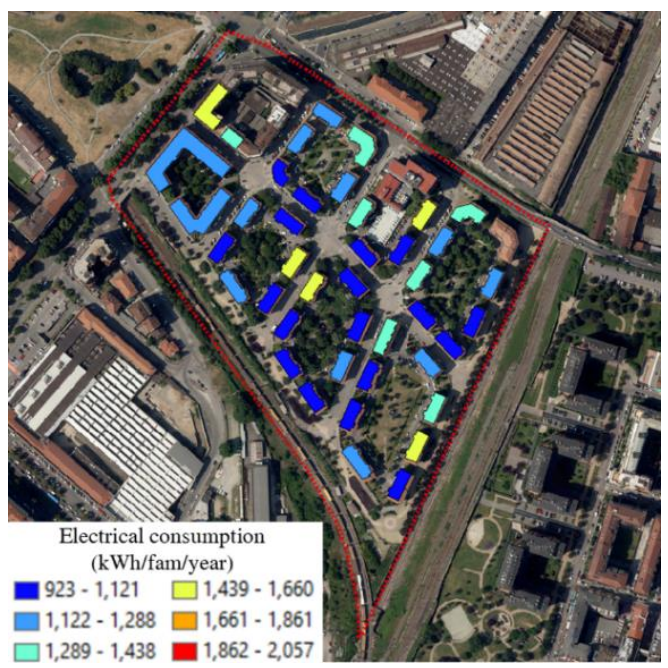

Figure 13. Annual consumption per family in Arquata
Following the results at neighborhood level, comparing Crocetta and Arquata districts, were described. As previous mentioned (see Table 4), a first parameter investigated was that the electricity consumption per family in the richest area, Crocetta, was higher than the other (Figures 12 and 13). The analysis made at the district scale confirms that the national and regional requirements to become ECs are met. According to regional limits: (i) the electrical contiguity is verified; (ii) the amount of electricity consumption of the two districts exceeds the limit of $0.5 \mathrm{GWh} /$ year (the consumption is 1.9 and $1.2 \mathrm{GWh} /$ year for Crocetta and Arquata respectively); (iii) the annual self-consumption from solar energy is higher than $70 \%$; (iv) there is a plurality of energy producers and consumers. In analogy to the analysis made at the building level, the scenarios analyzed at district level were: S1 without constraints, S2 with $S C / P \geq 70 \%$, and from S3 onwards with $S C / C \geq 50-60-\ldots$ up to the maximum achievable (the BT enters the optimal configuration from S3 onwards when $S C / C$ constraint was added). Knowing that the maximum installable PV power and the annual electrical consumption are: 2,233 kW and 1,938 MWh in Crocetta and 1,527 kW and 1,185 MWh in Arquata, from Table 7 emerged that:

- In both districts, referring to scenario $\mathrm{S} 2$, it is not necessary to use the maximum PV power, and the $S C / P$ constrain $(70 \%)$ by installing $756 \mathrm{~kW}$ of PV in Crocetta and $461 \mathrm{~kW}$ of PV in Arquata was respected.

- In Crocetta district, imposing a constraint of at least $70 \%$ self-consumption, at most it is possible to reach an $\mathrm{SC} / \mathrm{C}$ of $53 \%$, by installing $1.36 \mathrm{~kW} /$ family of $\mathrm{PV}$ and 1.56 $\mathrm{kWh} /$ family of BT (S4).

- In Arquata district, imposing a constraint of at least $70 \%$ self-consumption, at most it is possible to reach an $S C / C$ of $67 \%$, by installing $1.31 \mathrm{~kW} /$ family of PV and 1.97 $\mathrm{kWh} /$ family of BT (S6).

- Since in Arquata district the electrical consumption per family is lower than the other district (see Table 4), it is possible to have greater self-sufficiency with the same self-consumption. At the same time, the values of potential PV area per family in Arquata are lower than in Crocetta. Therefore, in these two districts, the energy consumption has a greater influence than the potential PV area on the self-sufficiency achievable.

- Compared to the analysis at building scale, with the establishment of an EC at district level it is possible to have a self-consumption greater than $70 \%$ and good selfsufficiency (that varies between $53 \%$ and $67 \%$ ) with reasonable $\mathrm{PV}$ and $\mathrm{BT}$ sizes.

Table 7. Annual results at district level

\begin{tabular}{ccccccc}
\hline & \multicolumn{3}{c}{ Crocetta } & \multicolumn{3}{c}{ Arquata } \\
& Input & \multicolumn{2}{c}{ Output } & Input & \multicolumn{2}{c}{ Output } \\
& $\boldsymbol{S C / C}$ & PV & BT & SC/C & PV & BT \\
& \% & kW & kWh & \% & kW & kWh \\
\hline S1 & 32 & 1,205 & 0 & 31 & 686 & 0 \\
S2 & 27 & 756 & 0 & 27 & 461 & 0 \\
S3 & 50 & 1,498 & 1,580 & 50 & 939 & 1029 \\
S4 & 53 & 1,592 & 1,831 & 60 & 1,149 & 1,538 \\
S5 & - & - & - & 66 & 1,237 & 1,962 \\
S6 & - & - & - & 67 & 1,277 & 1,919 \\
\hline
\end{tabular}

Figures 14 and 15 show in detail the sizes of PV and BT installed according to different values of $S C / C$, maintaining the $S C / P$ greater than or equal to $70 \%$ (from S2 to $\mathrm{S} 4$ or $\mathrm{S} 6$ ). 


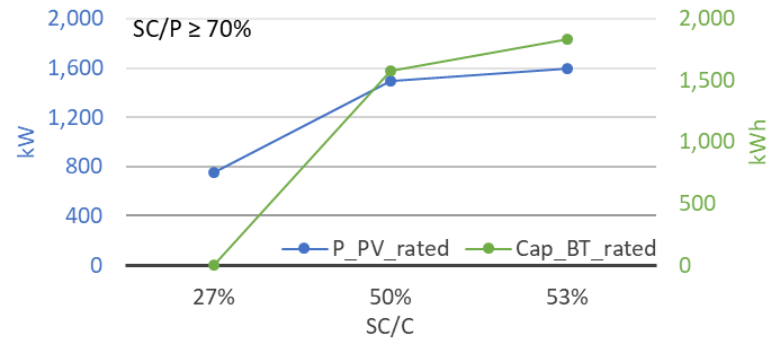

Figure 14. Crocetta district: PV installed power and BT capacity according to different $S C / C$ values and $S C / P \geq 70 \%$

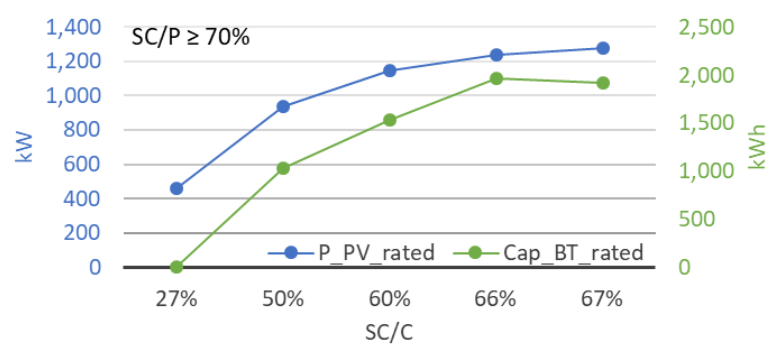

Figure 15. Arquata district: $P V$ installed power and BT capacity according to different $S C / C$ values and $S C / P \geq 70 \%$

Figures 16 and 17 show the influence on the system operation when considering different values of $S C / C$ for two different days of the year.

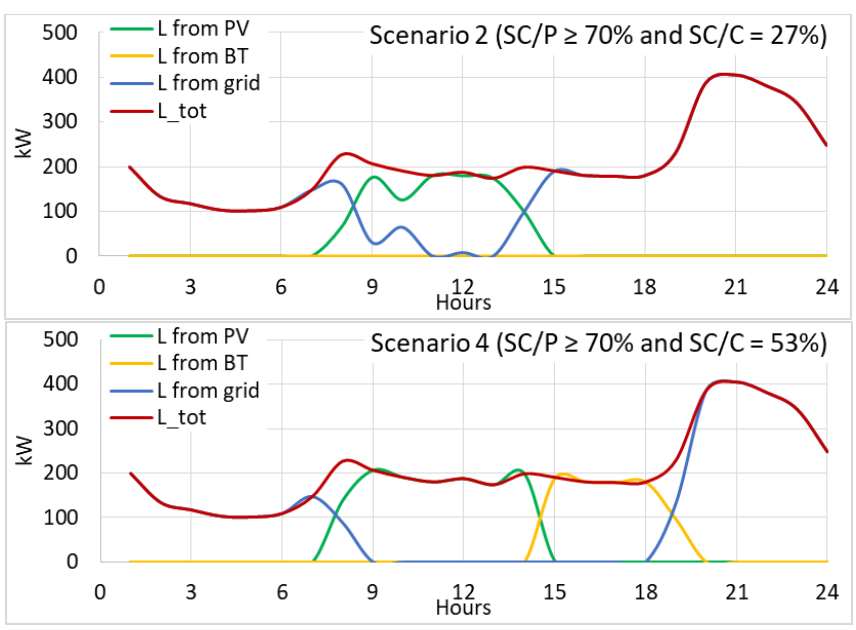

Figure 16. Crocetta district: December $18^{\text {th }}, 2017$

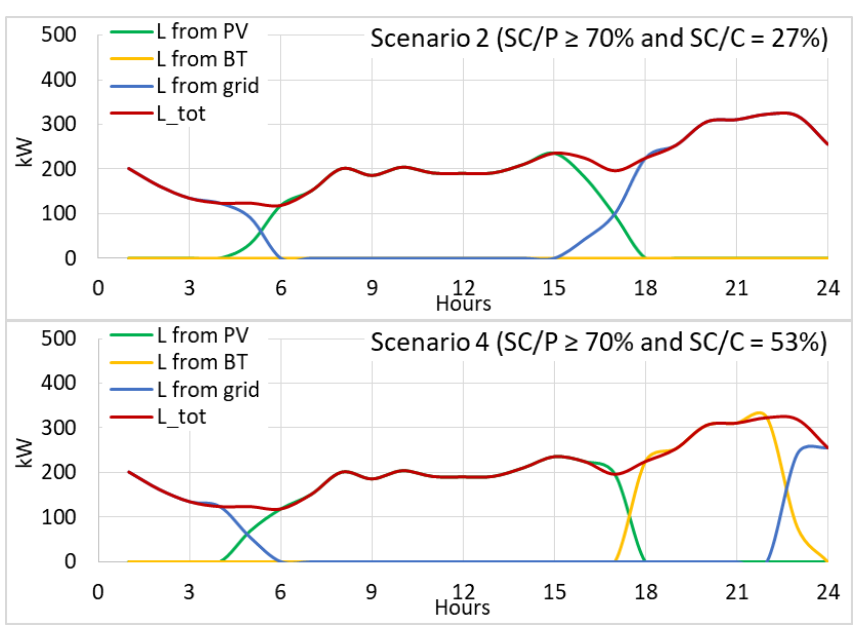

Figure 17. Crocetta district: August $24^{\text {st }}, 2017$
Figure 16 reports the hourly results of Crocetta district referring to December $18^{\text {th }} 2017$. In S4 it is possible to observe that from 3 to $6 \mathrm{pm}$ there was no availability of PV and the energy was not taken from the grid (as in S2) but the energy demand was covered by the BT. In the summer (Figure 17), the PV production was obviously higher than in the winter period and the BT can cover the energy demand from 6 to $11 \mathrm{pm}(\mathrm{S} 3)$.

Is moving to the district level, it is possible to satisfy the EC requirements by achieving a good level of selfsufficiency for all the buildings belonging to the EC. It should also be considered that an EC can benefit from higher incentives than a configuration at single building level (National Decree of $15^{\text {th }}$ September 2020). The economic aspect will be more in depth explored in future work.

\section{CONCLUSIONS}

In the effort to reduce the impact of energy consumption, the city can play a significant role by increasing selfconsumption $(S C / P)$ and self-sufficiency $(S C / C)$. This work describes a methodology to improve the $S C / P$ and $S C / C$ in high-density built context combining multiple homes at city level. The methodology was applied to two districts located in the city of Turin, Italy. Results show that at building level it is possible to activate the collective self-consumption mechanism, given that National and Regional requirements are respected. At the same time, at district scale it is possible to establish an REC in order to have a higher level of selfsufficiency for the whole group of residential buildings. Simulated scenarios show how imposed constraints on selfsufficiency and self-consumption rates can widely affect the optimal capacity of installed PV and storage units. Minimum targets on the self-sufficiency of buildings will drive the installation of more PV capacity and storage capacity. On the other hand, a set minimum ratio of self-consumption will lead to less solar installations and no role of batteries.

This study also shows that in an urban environment with buildings that have the same orientation and type of user, high levels of $S C / C$ and $S C / P$ are more easily achieved with low and compact buildings. In cities, however, the typical form of the building is a big and compact condominium, so to improve $S C / C$ and $S C / P$ it is necessary to move from the building scale to the district scale. From this first investigation, it emerges that the shape of the building has a significant influence on $S C / C$ and $S C / P$, therefore the urban context of a neighborhood is fundamental to improve energy efficiency at city level. In particular, to produce energy from RESs, it is necessary to mediate the urban form with energy productivity. Urban planning policies promote a building development in height, in order to reduce permeable surfaces; but with this type of urban development, the energy productivity from solar decreases. For solar technologies, it is necessary to build volumes compatible with the available roof surface.

Future work will take into account the concept of urban form and building shape with the aim to improve $S C / P$ and $S C / C$. In addition, the existing incentives introduced by the Italian legislation for the promotion of ECs and the use of renewable energy technologies financing mechanism will be considered in the economic analysis. Given that income significantly affects energy supply, the aspect of energy poverty will be also investigated. 


\section{REFERENCES}

[1] Lowitzsch, J., Hoicka, C.E., Van Tulder, F.J. (2020). Renewable energy communities under the 2019 European clean energy package-Governance model for the energy clusters of the future?. Renewable and Sustainable Energy Reviews, 122: 109489. https://doi.org/10.1016/j.rser.2019.109489

[2] Wang, C., Cheng, X., Shuai, C., Huang, F., Zhang, P., Zhou, M., Li, R. (2020). Evaluation of energy and environmental performances of solar photovoltaic-based targeted poverty alleviation plants in China. Energy for Sustainable Development, 56: 73-87. https://doi.org/10.1016/j.esd.2020.04.003

[3] Li, J., Wang, Z., Cheng, X., Shuai, J., Shuai, C., Liu, J. (2020). Has solar PV achieved the national poverty alleviation goals? Empirical evidence from the performances of 52 villages in rural China. Energy, 201: 117631. https://doi.org/10.1016/j.energy.2020.117631

[4] Luthander, R., Nilsson, A.M., Widén, J., Åberg, M. (2019). Graphical analysis of photovoltaic generation and load matching in buildings: A novel way of studying self-consumption and self-sufficiency. Applied Energy, 250:

748-759. https://doi.org/10.1016/j.apenergy.2019.05.058

[5] Delponte, I., Schenone, C. (2020). RES implementation in urban areas: An updated overview. Sustainability, 12(1): 382. https://doi.org/10.3390/su12010382

[6] Perea-Moreno, M.A., Hernandez-Escobedo, Q., PereaMoreno, A.J. (2018). Renewable energy in urban areas: Worldwide research trends. Energies, 11(3): 577. https://doi.org/10.3390/en11030577.

[7] Pavani, P., Bak-Jensen, B., Pillai, J.R. (2019). Maximizing the self-consumption of solar-PV using Battery energy storage system in Samsø-Marina. In 2019 IEEE PES Innovative Smart Grid Technologies Europe (ISGT-Europe), pp. 1-5. https://doi.org/10.1109/ISGTEurope.2019.8905498

[8] Gagliano, A., Nocera, F. (2017). Analysis of the performances of electric energy storage in residential applications. International Journal of Heat and Technology, 35(1): S41-S48. https://doi.org/10.18280/ijht.35Sp0106

[9] Struth, J., Kairies, K.P., Leuthold, M., Aretz, A., Bost, M., Gährs, S., ... \& Sauer, D.U. (2013). PV-Benefit: A critical review of the effect of grid integrated pvstorage-systems. In 8th International Renewable Energy Storage Conference and Exibition. Berlin: Institut für ökologische Wirtschaftsforschung.

[10] Dehler, J., Keles, D., Telsnig, T., Fleischer, B., Baumann, M., Fraboulet, D., Faure-Schuyer, A., Fichtner, W. (2017). Chapter 27 - Self-Consumption of Electricity from Renewable Sources. In: Europe's Energy Transition, 225-236. https://doi.org/10.1016/B978-0-12-809806-6.00027-4

[11] Zhang, J., Xu, L., Shabunko, V., Tay, S.E.R., Sun, H., Lau, S.S.Y., Reindl, T. (2019). Impact of urban block typology on building solar potential and energy use efficiency in tropical high-density city. Applied Energy, 240:

$513-533$ https://doi.org/10.1016/j.apenergy.2019.02.033

[12] El Kontar, R., Jin, X. (2020). A framework for optimal placement of rooftop photovoltaic: Maximizing solar production and operational cost savings in residential communities. ASME Journal of Engineering for Sustainable Buildings and Cities, 1(4). https://doi.org/10.1115/1.4049135

[13] Wang, Z., Hong, T. (2020). Generating realistic building electrical load profiles through the Generative Adversarial Network (GAN). Energy and Buildings, 224:

110299 https://doi.org/10.1016/j.enbuild.2020.110299

[14] Serrano-Guerrero, X., Escrivá-Escrivá, G., Roldán-Blay, C. (2018). Statistical methodology to assess changes in the electrical consumption profile of buildings. Energy and Buildings, 164: 99-108. https://doi.org/10.1016/j.enbuild.2017.12.059

[15] Mutani, G., Pastorelli, M., de Bosio, F. (2015). A model for the evaluation of thermal and electric energy consumptions in residential buildings: The case study in Torino (Italy). In 2015 International Conference on Renewable Energy Research and Applications (ICRERA), pp. 1399-1404. https://doi.org/10.1109/ICRERA.2015.7418637

[16] Delmastro, C., Mutani, G., Schranz, L., Vicentini, G. (2015). The role of urban form and socio-economic variables for estimating the building energy savings potential at the urban scale. International Journal of Heat and Technology, 33(4): 91-100. https://doi.org/10.18280/ijht.330412

[17] Mutani, G., Santantonio, S, Brunetta, G., Caldarice, O., Demichela, M. (2021). An energy community for territorial resilience. The Measurement of the Risk of Energy Supply Blackout. Energy Build. https://doi.org/10.1016/j.enbuild.2021.110906.

[18] Todeschi, V., Mutani, G., Baima, L., Nigra, M., Robiglio, M. (2020). Smart solutions for sustainable cities-The re-coding experience for harnessing the potential of urban rooftops. Applied Sciences, 10(20): 7112. https://doi.org/10.3390/app10207112.

[19] Mutani, G., Todeschi, V. (2020). Low-carbon strategies for resilient cities: A place-based evaluation of solar technologies and green roofs potential in urban contexts TECNICA ITALIANA-Italian Journal of Engineering Science, 64(2-4): 193-201. https://doi.org/10.18280/tiijes.642-410

[20] Hong, T., Lee, M., Koo, C., Jeong, K., Kim, J. (2017). Development of a method for estimating the rooftop solar photovoltaic (PV) potential by analyzing the available rooftop area using Hillshade analysis. Applied Energy, 194: 320-332. https://doi.org/10.1016/J.APENERGY.2016.07.001

[21] Suomalainen, K., Wang, V., Sharp, B. (2017). Rooftop solar potential based on LiDAR data: Bottom-up assessment at neighbourhood level. Renewable Energy, 111: $463-475$ https://doi.org/10.1016/J.RENENE.2017.04.025

[22] Chatzipoulka, C., Compagnon, R., Nikolopoulou, M. (2016). Urban geometry and solar availability on façades and ground of real urban forms: using London as a case study. Solar Energy, 138: 53-66. https://doi.org/10.1016/J.SOLENER.2016.09.005

[23] Thebault, M., Clivillé, V., Berrah, L., Desthieux, G. (2020). Multicriteria roof sorting for the integration of photovoltaic systems in urban environments. Sustainable Cities and Society, 60: 102259. https://doi.org/10.1016/j.scs.2020.102259

[24] Maleki, A., Askarzadeh, A. (2014). Comparative study 
of artificial intelligence techniques for sizing of a hydrogen-based stand-alone photovoltaic/wind hybrid system. International Journal of Hydrogen Energy, 39(19):

9973-9984.

https://doi.org/10.1016/j.ijhydene.2014.04.147

[25] Schopfer, S., Tiefenbeck, V., Staake, T. (2018) Economic assessment of photovoltaic battery systems based on household load profiles. Applied Energy, 223: 229-248.

https://doi.org//10.1016/j.apenergy.2018.03.185

[26] Moretti, L., Polimeni, S., Meraldi, L., Raboni, P., Leva, S., Manzolini, G. (2019). Assessing the impact of a twolayer predictive dispatch algorithm on design and operation of off-grid hybrid microgrids. Renewable Energy, 143:

$1439-1453$ https://doi.org/10.1016/j.renene.2019.05.060

[27] Marocco, P., Ferrero, D., Gandiglio, M., Ortiz, M.M., Sundseth, K., Lanzini, A., Santarelli, M. (2020). A study of the techno-economic feasibility of $\mathrm{H}_{2}$-based energy storage systems in remote areas. Energy Conversion and Management, 211: 112768. https://doi.org/10.1016/j.enconman.2020.112768
[28] Pavone, F. (2014). NONO RAPPORTO SULL'ENERGIA: Provincia di Torino. (in Italian).

[29] Goy, S., Sancho-Tomás, A. (2019). 4-Load management in buildings. In: Eicker UBT-UES for LCC, Academic Press, 137-179. https://doi.org/10.1016/B978-0-12-811553-4.00004-4

\section{NOMENCLATURE}

BT Battery

NPC Net present cost

OMC Operation and maintenance cost

PSO Particle swarm optimization

PV Photovoltaic technology

C Consumption (total used energy)

SC Self-consumption (consumed share of energy produced)

$\mathrm{P} \quad$ Energy production (with PV systems)

$\mathrm{SC} / \mathrm{P} \quad$ Self-consumption index

SC/C Self-sufficiency index 